\title{
Efficacy of different doses of dexmedetomidine as a rapid bolus for children: a double-blind, prospective, randomized study
}

Fang Chen ${ }^{1,2}$, Chengyu Wang ${ }^{2}$, Yi Lu², Mengmeng Huang ${ }^{2}$ and Zhijian Fu ${ }^{1 *}$

\begin{abstract}
Background: Dexmedetomidine (DEX), a highly sensitive $a_{2}$-adrenoceptor agonist that possesses anxiolytic, sedative, and analgesic effects, has been documented as a preventative and treatment for emergence agitation (EA). The therapeutic should be given as a loading dose that is infused during a $10 \mathrm{~min}$ period, but if a rapid bolus injection is deemed to be hemodynamically appropriate, it would be a more opportune route of administration. So we studied the efficacy of different doses of DEX as a rapid bolus for children to prevent and treat EA.

Methods: One hundred patients were enrolled and randomly divided into five groups: the control group (group $D_{1}$ ), the $0.25 \mu \mathrm{g} / \mathrm{kg}$ DEX group (group $D_{2}$ ), the $0.5 \mu \mathrm{g} / \mathrm{kg}$ DEX group (group $D_{3}$ ), the $0.75 \mu \mathrm{g} / \mathrm{kg}$ DEX group (group $\mathrm{D}_{4}$ ), and the $1 \mathrm{\mu g} / \mathrm{kg}$ DEX group (group $\mathrm{D}_{5}$ ). Heart rate (HR), mean blood pressure (MBP) and blood oxygen saturation $\left(\mathrm{SaO}_{2}\right)$ were recorded immediately before the study drug injection (baseline) and every minute for 5 min thereafter and at the time points of the skin cut and hernial sac pull. EA and pain were assessed in the post -anesthesia care unit, and any complementary medicine and adverse events were recorded too.

Results: The incidence of EA was significantly decreased in group $D_{4}$ and group $D_{5}$ compared with $D_{1}$.All groups exhibited similar baseline HR and MBP. After administered, HR and MBP were significantly decreased in all DEX group compared with group $D_{1}$. In groups $D_{3}, D_{4}$ and $D_{5}$, the minimal HR was decreased significantly compared with the groups $D_{1}$ and duration time of minimal HR significantly prolonged in group $D_{5}$, but no patient needed treatment. As the dosage increased, the recovery time was significantly prolonged. There were no significant differences in occurrence time of minimal $H R$, the incidence of complementary medicine and adverse events among groups.
\end{abstract}

Conclusion: Rapid intravenous injection (IV) bolus administration of 0.75 and $1.0 \mu \mathrm{g} / \mathrm{kg}$ of DEX could improve the recovery profile by reducing the incidence of EA in children. Although its use resulted in a transient decreases in $\mathrm{HR}$ and MBP, DEX was clinically well-tolerated in children.

Trial registration: No. ChiCTR-IPR-17010658. Registered 17 February 2017.

Keywords: Dexmedetomidine, Children, Rapid injection, Emergence agitation

\footnotetext{
*Correspondence: zhijian_fu@163.com

'Department of Pain Management, Shandong Provincial Hospital affiliated to

Shandong University, 324 Jingwu Road, Jinan 250021, China

Full list of author information is available at the end of the article
}

(c) The Author(s). 2018 Open Access This article is distributed under the terms of the Creative Commons Attribution 4.0 International License (http://creativecommons.org/licenses/by/4.0/), which permits unrestricted use, distribution, and reproduction in any medium, provided you give appropriate credit to the original author(s) and the source, provide a link to the Creative Commons license, and indicate if changes were made. The Creative Commons Public Domain Dedication waiver (http://creativecommons.org/publicdomain/zero/1.0/) applies to the data made available in this article, unless otherwise stated. 


\section{Background}

Dexmedetomidine (DEX), a highly selective $\alpha_{2}$-adrenoreceptor agonist, offers anxiolytic, sedative, and analgesic effects with negligible respiratory depression [1-3].DEX has been approved for use in adults, but the US Food and Drug Administration has not approved the drug for children. However, DEX has been documented in pediatric patients as a premedication, a sedative in the pediatric intensive care unit, in conjunction with inhaled anesthetic agents, and as a therapeutic for the prevention and treatment of emergence agitation (EA) following general anesthesia [4-6]. EA, particularly in children, presents a great challenge to good patient care $[7,8]$. While 2-, 5-, or 10-min DEX infusions lower the occurrence of EA in pediatric patients $[9,10]$, it is typically not convenient to administer a bolus infusion in the clinical area of an elevated-turnover work-intensive pediatric anesthesiology unit. A quickly administered bolus injection, if deemed to be hemodynamically appropriate, would be a more opportune route of administration to avert and treat EA. Jooste $\mathrm{EH}$ et al. [11] had observed that rapid IV bolus administration of DEX in 12 children who underwent heart

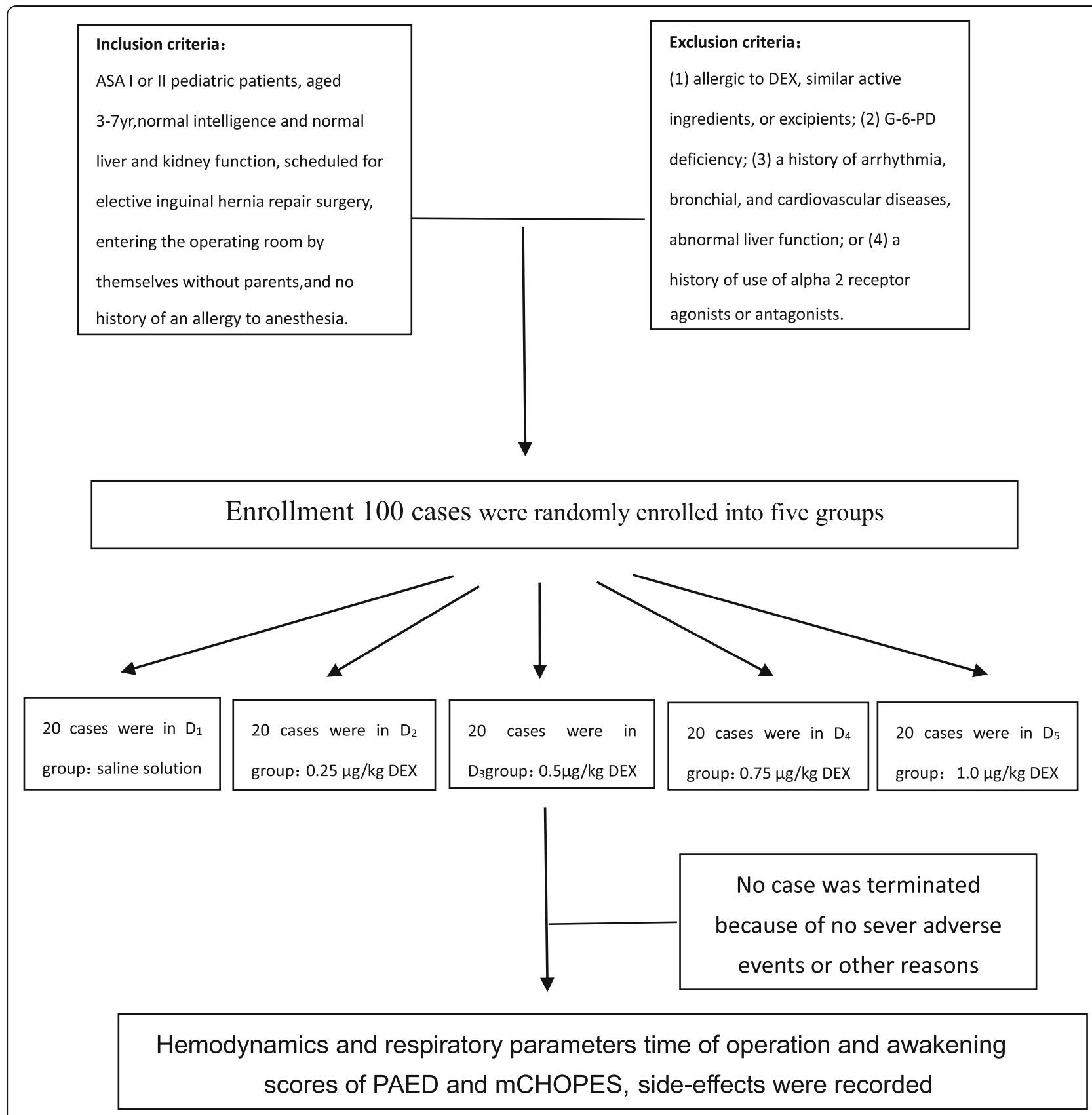

Fig. 1 The flow chart of the study 
Table 1 Demographic and surgical characteristics of patients

\begin{tabular}{llllll}
\hline Variable & Group $D_{1}$ & Group $D_{2}$ & Group $D_{3}$ & Group $_{4}$ & Group $D_{5}$ \\
\hline Age, median (IQR), yr & $4(4-5)$ & $5(3-6)$ & $4(3.5-5)$ & $4(3-4.5)$ & $4(3-5)$ \\
Male/Female, No./No. & $17 / 3$ & $17 / 3$ & $16 / 4$ & $16 / 4$ & $16 / 4$ \\
Weight, median (IQR), kg & $17.0(16.0-20.0)$ & $18.3 \pm 3.95$ & $17.0(15.0-17.75)$ & $16.4 \pm 3.28$ & $18.5 \pm 3.76$ \\
Duration of surgery, median (IQR), min & $14.4 \pm 5.95$ & $11.5(10.0-14.5)$ & $12.0(9.5-14.0)$ & $11.0(9.5-20.5)$ & $11.5(9.0-13.0)$ \\
\hline
\end{tabular}

There were no statistically significant differences $(P>0.05)$ among the groups

transplants was clinically well-tolerated, although its use resulted in a transient but significant increase in systemic and pulmonary blood pressure and a decrease in heart rate (HR). In addition, Hauber JA et al. [12] documented that fast IV bolus administration of $0.5 \mu \mathrm{g} / \mathrm{kg}$ DEX improved pediatric patients' recuperation profile by lowering the occurrence of EA. Although a statistically significant change in hemodynamics was observed, no patient required intervention for hemodynamic changes. However, the aforementioned studies used either a small sample study or only one dose. DEX is often used to avert and treat postoperative agitation in dosages of $0.25-1 \mu \mathrm{g} / \mathrm{kg}$, and many clinical institutions now commonly administer DEX as a rapid (under $5 \mathrm{~s}$ ) IV bolus. Therefore, our study examined the efficacy of different doses of DEX as a rapid bolus for prevention and treating EA in pediatric patients.

\section{Methods}

\section{Design and setting}

We conducted a double-blind randomized controlled trial in 100 patients in the 2nd Affiliated Hospital \& Yuying Children's Hospital of WenZhou Medical University.

\section{Patient selection}

According to the preliminary experimental results, two groups with the smallest difference in the five groups were analyzed with $\mathrm{a}=0.05, \mathrm{~b}=0.2$, and the difference between groups was 0.4 .The calculated sample size was 16 cases per group. Considering the $20 \%$ sample exfoliate rate, we need 20 cases per group, a total of 100 cases sample size.

This clinical trial was registered at http://www.chictr.org.cn (No. ChiCTR-IPR-17010658), and conducted from April 2017 to October 2017. After obtaining informed written consent from parent of each child, 100 ASA I or II pediatric patients, aged 3-7 yr., were

Table 2 Incidence of Emergence Agitation (PAED > 12)

\begin{tabular}{llll}
\hline Groups & Number & Incidence $(\%)$ & $P$ value \\
\hline Group $D_{1}$ & 6 & $30 \%$ & \\
Group $D_{2}$ & 1 & $5 \%$ & $P=0.096$ \\
Group $D_{3}$ & 1 & $5 \%$ & $P=0.096$ \\
Group $D_{4}$ & 0 & $0 \%$ & $P<0.001$ \\
Group $D_{5}$ & 0 & $0 \%$ & $P<0.001$ \\
\hline
\end{tabular}

"Compared with Group $D_{1}$ randomly (Random number method) enrolled into five groups: the control group (group $D_{1}$ ), the $0.25 \mu \mathrm{g} / \mathrm{kg}$ DEX group (group $\mathrm{D}_{2}$ ), the $0.5 \mu \mathrm{g} / \mathrm{kg} \mathrm{DEX}$ group (group $\mathrm{D}_{3}$ ), the $0.75 \mu \mathrm{g} / \mathrm{kg} \mathrm{DEX}$ group (group $\mathrm{D}_{4}$ ), and the $1 \mu \mathrm{g} / \mathrm{kg}$ DEX group (group $\mathrm{D}_{5}$ ). Inclusion criteria were: normal intelligence and normal liver and kidney function, scheduled for elective inguinal hernia repair surgery, entering the operating room by themselves without parents, and no history of an allergy to anesthesia.

Patients were excluded if they met any of the following criteria: (1) allergic to DEX, similar active ingredients, or excipients; (2) G-6-PD deficiency; (3) a history of arrhythmia, bronchial, and cardiovascular diseases, abnormal liver function; or (4) a history of use of alpha 2 receptor agonists or antagonists (Fig. 1).

\section{Medication}

No premedication was administered. A peripheral venous catheter was inserted approximately $2 \mathrm{~h}$ prior to surgery (while in the unit). EMLA cream (lidocaine 2.5\% and prilocaine 2.5\%, Astra Zeneca Inc., Sweden) was used to ease venous cannulation. HR, noninvasive arterial blood pressure, blood oxygen saturation ( $\mathrm{SaO} 2)$, electrocardiogram (ECG), and bispectral index (BIS) were monitored. After preoxygenation via face mask, anesthesia was induced with propofol $2-3 \mathrm{mg} / \mathrm{kg}$ and inhalation of 6 vol\% sevoflurane. After the pupils were fixed, the laryngeal mask airway (LMA) was inserted and the ilioinguinal/iliohypogastric nerve block was performed by ultrasound guidance to relieve postoperative pain. Anesthesia was maintained with 2-3 vol\% sevoflurane to maintained BIS from 40 to 60 and retaining spontaneous respiration. After the vital signs were stable, study groups received a rapid bolus injection of different doses of DEX (Jiangsu singch pharmaceutical co., LTD) at a rate of less than $5 \mathrm{~s}$, while patients in the control group received saline in an equal volume. When the surgery was completed, every one of the patients was moved to the post-anesthesia care unit (PACU), and the children naturally regained consciousness.

\section{Data collection}

$\mathrm{HR}$, mean blood pressure (MBP), and $\mathrm{SaO}_{2}$ were recorded immediately before the study drug injection 


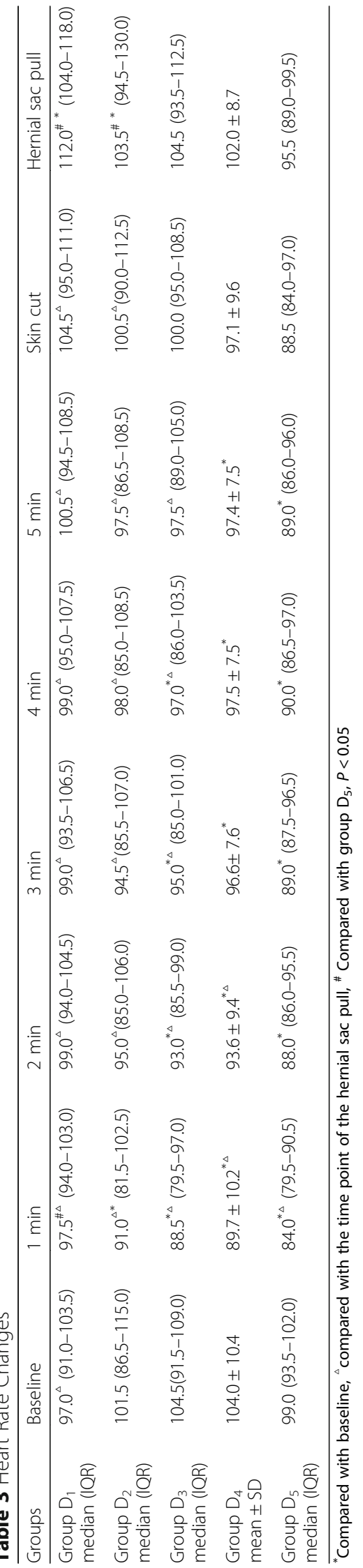


(baseline), every minute for 5 min thereafter, and at the time points of the skin cut and hernial sac pull. EA was assessed by the study staff upon arrival in the PACU using the Pediatric Anesthesia Emergence Delirium (PAED) scale (0-20 scale), with a score of $>12$ considered to be a diagnosis of EA [12]. Propofol $1 \mathrm{mg} / \mathrm{kg}$ was administered via IV for EA if the patient was determined to be pain-free and when the parent or caregiver was unable to comfort the child. Pain was evaluated using the Modified Children's Hospital of Eastern Ontario Pain Scale (m-CHOPES), and intravenous fentanyl $0.5 \mu \mathrm{g} / \mathrm{kg}$ was administered if the score was $\geq 7$. The time of operation and awakening, and any side effects, such as respiratory and cardiovascular depression were recorded. Any supplementary postoperative drugs were also recorded. Finally, patients with an Alderete score $\geq 9$ were sent back to the ward.

\section{Statistical analysis}

All of the data are presented as mean \pm standard deviation (SD), median (interquartile range), or number (\%), as appropriate. The measurement data was analyzed by Shapiro-Wilk. The normal distribution data which satisfied the homogeneity test of variance was tested by ANOVA, if not, by Kruskal-Wallis. The abnormal distribution data was analyzed by Kruskal-Wallis to compare among groups. Pearson's chi-squared test was used to assess the comparison among groups in count data. The repeated measurement data (MAP and HR) was analyzed by two-way ANOVA, and the comparisons of intra-group and among groups were analyzed by bonferroni. Data were analyzed using SPSS software (SPSS 16.0, SPSS, Inc., Chicago, IL, USA). A $p$ value of less than 0.05 was considered to be a significant difference.

\section{Results}

There were 100 pediatric patients who were enrolled and randomly divided into five groups. As seen in Table 1, there were no significant demographic and surgical characteristic differences among the groups.

The incidence of EA was significantly lower in groups $D_{4}$ and $D_{5}$, and a trend of fewer was observed in group $\mathrm{D}_{2}$ and $\mathrm{D}_{3}$ (Table 2).

There were no significant differences in the basal $H R$ among the five groups. In group $D_{1}$, there were no significant differences among the basal $H R$ and every minute for $5 \mathrm{~min}$ thereafter, but the HR at the point of the hernial sac pull was increased significantly compared with the baseline. In group $\mathrm{D}_{2}$, the HR was decreased at $1 \mathrm{~min}$ compared with the baseline, and then returned to the baseline at 2, 3, 4 and $5 \mathrm{~min}$, and the points of skin cut, but the HR at the point of the hernial sac pull was increased significantly compared with the baseline. In group $D_{3}$, the
HR was decreased at 1, 2,3 and 4 min compared with the baseline, and the HR returned to the baseline at $5 \mathrm{~min}$, the points of skin cut and hernial sac pull. In groups $\mathrm{D}_{4}$ and $\mathrm{D}_{5}$, the $\mathrm{HR}$ was decreased at $1,2,3,4$ and 5 min compared with the baseline, and the HR returned to the baseline at the time point of the skin cut and hernial sac pull (Table 3).

The minimal HR of groups $\mathrm{D}_{3}, \mathrm{D}_{4}$, and $\mathrm{D}_{5}$ were decreased significantly compared with groups $\mathrm{D}_{1}$. And the duration time of minimal HR was significantly prolonged in group $\mathrm{D}_{5}$ compared with group $\mathrm{D}_{1}$. There were no significant differences in occurrence time of minimal HR among groups (Table 4).

There were no significant differences in the basal MBP among the five groups. In group $D_{1}$, there were no significant differences among the basal MBP and every minute for 5 min thereafter, but the MBP at the point of the hernial sac pull was increased significantly compared with the baseline. In group $\mathrm{D}_{2}$, the MBP was decreased at 2, 3, 4, and 5 min compared with the baseline, and the MBP returned to the baseline at the point of skin cut and hernial sac pull. In group $\mathrm{D}_{3}$ and $\mathrm{D}_{4}$, the $\mathrm{MBP}$ was decreased at 3,4 , and $5 \mathrm{~min}$ compared with the baseline, and the MBP returned to the baseline at the point of skin cut and hernial sac pull. In group $D_{5}$, the $\mathrm{MBP}$ was decreased at $5 \mathrm{~min}$ and the points of the skin cut and hernial sac pull compared with the baseline (Table 5).

There were no significant differences in incidencerate of complementary medicine, adverse events, and bradycardia (we defined bradycardia as HR decrease of $\geq 30 \%$ during the 5-min observation period postdexmedetomidine bolus, compared to predexmedetomidine bolus baseline values). There were eight patients who had a $30 \%$ decrease from the baseline of HR, and none of the patients required treatment for bradycardia. Four patients needed propofol to treat EA, and no one needed treatment for bradycardia, pain, or other adverse events, including cough, headache, and vomiting (Table 6). All of the patients with spontaneous respiration could maintain $\mathrm{SaO}_{2} \geq 98 \%$. There were significant differences in the recovery time between every two groups $(P<0.05)$ (Table 7).

Table 4 Minimal Heart Rate

\begin{tabular}{llll}
\hline Groups & Minimal & Duration time(s) & Occurrence time(s) \\
\hline Group $D_{1}$ & $92 \pm 12$ & $2.0(1.0-3.5)$ & $30.0(20.0-42.5)$ \\
Group $D_{2}$ & $88 \pm 16$ & $2.0(2.0-6.0)$ & $42.0(39.0-49.0)$ \\
Group $D_{3}$ & $83 \pm 11^{*}$ & $5.0(3.0-6.5)$ & $38.5(35.0-43.0)$ \\
Group $D_{4}$ & $84 \pm 11^{*}$ & $3.0(2.0-5.0)$ & $41.0(34.5-50.0)$ \\
Group $D_{5}$ & $81 \pm 8^{*}$ & $6.0(2.0-9.0)^{*}$ & $41.0(32.5-49.0)$ \\
\hline
\end{tabular}

${ }^{*}$ Compared with group $D_{1}$ respectively, $P<0.05$ 
Table 5 MBP Changes [median (IQR)]

\begin{tabular}{|c|c|c|c|c|c|c|c|c|}
\hline Groups & Baseline & $1 \mathrm{~min}$ & $2 \min$ & $3 \min$ & $4 \min$ & $5 \mathrm{~min}$ & Skin cut & $\begin{array}{l}\text { Hernial sac } \\
\text { pull }\end{array}$ \\
\hline $\begin{array}{l}\text { Group } \\
D_{1}\end{array}$ & $\begin{array}{l}58.0^{\triangle}(56.5- \\
62.0)\end{array}$ & $58.0(57.0-62.5)$ & $\begin{array}{l}58.0^{\triangle}(56.0- \\
61.5)\end{array}$ & $\begin{array}{l}58.0^{\triangle}(56.0- \\
61.0)\end{array}$ & $\begin{array}{l}57.0^{\Delta}(56.0- \\
58.5)\end{array}$ & $\begin{array}{l}57.5^{\Delta}(55.0- \\
59.5)\end{array}$ & $61.5(56.0-64.5)$ & $\begin{array}{l}64.5^{*}(60.0- \\
69.5)\end{array}$ \\
\hline $\begin{array}{l}\text { Group } \\
D_{2}\end{array}$ & $60.0(53.5-66.5)$ & $58.5(51.5-65.0)$ & $\begin{array}{l}57.0^{* \Delta}(49.5- \\
61.0)\end{array}$ & $\begin{array}{l}58.0^{*}(50.0- \\
60.5)\end{array}$ & $57.0^{*}(48.0-60.5)$ & $\begin{array}{l}57.0^{* \Delta}(49.5- \\
60.5)\end{array}$ & $\begin{array}{l}57.0^{\Delta}(52.0- \\
60.0)\end{array}$ & $\begin{array}{l}62.0(55.0- \\
70.5)\end{array}$ \\
\hline $\begin{array}{l}\text { Group } \\
D_{3}\end{array}$ & $58.0(55.5-60.5)$ & $58.0(55.5-61.5)$ & $\begin{array}{l}55.5^{\Delta}(52.0- \\
58.0)\end{array}$ & $\begin{array}{l}53.0^{*}(51.0- \\
56.5)\end{array}$ & $\begin{array}{l}53.0^{*_{\Delta}}(51.0- \\
55.5)\end{array}$ & $53.0^{*}(51.0-56.0)$ & $54.5(51.0-57.5)$ & $\begin{array}{l}58.5(53.5- \\
61.5)\end{array}$ \\
\hline $\begin{array}{l}\text { Group } \\
D_{4}\end{array}$ & $59.0(55.0-65.5)$ & $59.5(57.5-67.0)$ & $56.5(53.0-61.0)$ & $\begin{array}{l}55.0^{*}(51.5- \\
60.0)\end{array}$ & $53.5^{*}(50.0-58.5)$ & $\begin{array}{l}55.0^{* \Delta}(49.5- \\
59.0)\end{array}$ & $57.5(50.5-61.0)$ & $\begin{array}{l}59.5(56.5- \\
64.0)\end{array}$ \\
\hline $\begin{array}{l}\text { Group } \\
D_{5}\end{array}$ & $57.0(54.0-63.0)$ & $\begin{array}{l}61.5^{\Delta}(57.5- \\
68.0)\end{array}$ & $54.5(51.0-65.0)$ & $54.0(49.0-60.0)$ & $53.0(49.5-60.5)$ & $52.5^{*}(50.0-56.5)$ & $\begin{array}{l}53.5^{*}(49.5- \\
59.0)\end{array}$ & $\begin{array}{l}52.5^{*}(48.5- \\
59.0)\end{array}$ \\
\hline
\end{tabular}

${ }^{*}$ Compared with Baseline, ${ }^{\triangle}$ compared with the time point of hernial sac pull, $P<0.05$

\section{Discussion}

Even without a pediatric label, additions to the literature on pediatric applications of DEX have risen in the last few years [4]. DEX has numerous properties that make it beneficial as a sedative and anesthetic; it has been documented to sedate in a manner that is similar to natural sleep, and it is used as an anxiolytic, analgesic, and sympatholytic [1, 2, 13]. In addition, it has an anesthetic-sparing impact with negligible respiratory depression, and it can be used to avert and treat postoperative EA [13]. The hemodynamic reactions of DEX are related to the rate of infusion and dose [5]. Although it is recommended that DEX is infused as a bolus over $10 \mathrm{~min}$, the $\mathrm{BP}$ and $\mathrm{HR}$ response are still present $[2,14]$. As doses of DEX get larger, hypotension and transient hypertension are greater. While there are many clinical encounters in the rapid bolus injection of DEX, there is minimal efficacy data that are accessible $[11,12,15]$.

In our study, we found that 0.75 and $1.0 \mu \mathrm{g} / \mathrm{kg}$ DEX rapid infusion could significantly reduce the incidence of EA, while 0.25 and $0.5 \mu \mathrm{g} / \mathrm{kg}$ DEX had the fewer trend. Hauber JA et al. [12] had found that $0.5 \mu \mathrm{g} / \mathrm{kg}$ DEX rapid infusion could reducing the incidence of EA. The difference may because different subjective evaluation of

Table 6 Comparison of complementary medicine, adverse events, and bradycardia [No. (\%)]

\begin{tabular}{llll}
\hline Groups & $\begin{array}{l}\text { Complementary } \\
\text { Medicine }\end{array}$ & Adverse events & Bradycardia $^{a}$ \\
\hline Group $D_{1}$ & $3(15 \%)$ & 0 & 0 \\
Group $D_{2}$ & 0 & 0 & $1(5 \%)$ \\
Group $D_{3}$ & $1(5 \%)$ & $3(15 \%)$ & $3(15 \%)$ \\
Group $D_{4}$ & 0 & $1(5 \%)$ & $2(10 \%)$ \\
Group $D_{5}$ & 0 & $1(5 \%)$ & $2(10 \%)$
\end{tabular}

There were no statistically significant differences $(P>0.05)$ among the groups ${ }^{a}$ Bradycardia was defined as HR decrease of $\geq 30 \%$ during the 5 -min observation period postdexmedetomidine bolus, compared to predexmedetomidine bolus baseline values the score of PAED and the smaller sample size. In addition, $0.5,0.75$ and $1.0 \mu \mathrm{g} / \mathrm{kg}$ DEX could reduce the surgical stress of the hernial sac pull. As the dosage increased, the recovery time was significantly prolonged, but there were no significant differences in the incidence of total adverse events. EA is a traumatic experience for children and their parents, and it can result in injury [16]. DEX has been well reported as an effective agent for EA, and the rapid bolus administration of DEX for the treatment of EA is more practical and timely than a 10-min infusion.

DEX could significantly decrease HR and MBP. The minimal HR was significantly lower after the administration of DEX in the dose of $0.5,0.75$ and $1 \mu \mathrm{g} / \mathrm{kg}$, and the duration time was significantly prolonged after $1.0 \mu \mathrm{g} / \mathrm{kg}$ DEX infusion, but no one needed treatment. In human and animal models, DEX has a biphasic blood pressure impact: a preliminary but transitory elevation in blood pressure accompanied by a long-lasting hypotensive effect that is induced by peripheral $\alpha_{2}$-adrenoreceptor and then central $\alpha_{2}$-adrenoreceptor stimulation [11, 12, 17]. Therefore DEX should be administered as a loading dose during a 10-min period to diminish the dose-dependent, biphasic, hemodynamic reaction. In our study, hypertension was not seen, this could have happened since the rapid infusion of DEX eradicated the time differential between the stimulation of the peripheral and central $\alpha_{2}$-adrenoreceptor.

Table 7 Recovery time (mean \pm SD)

\begin{tabular}{ll}
\hline Groups & Recovery time $(\mathrm{min})$ \\
\hline Group $D_{1}$ & $21.3 \pm 7.1$ \\
Group $D_{2}$ & $30.3 \pm 8.6$ \\
Group $D_{3}$ & $40.7 \pm 8.2$ \\
Group $D_{4}$ & $49.5 \pm 6.4$ \\
Group $D_{5}$ & $60.4 \pm 21.1$
\end{tabular}

There were significant differences in the recovery time between every two groups $(P<0.05)$ 
The general agreement seems to be that DEX is linked to minimal respiratory depression $[1,5,17,18]$. Our study found that the rapid injection of DEX can cause a decrease in tidal volume, but it does not affect $\mathrm{SaO}_{2}$ without special handling. This may because deep sedation and oral/pharyngeal anatomic frequently happened in deep sleep after the administration of DEX.

\section{Conclusion}

In conclusion, rapid infusion of DEX at dose of 0.75, and $1.0 \mu \mathrm{g} / \mathrm{kg}$ DEX could prevent EA. Even though the use of DEX resulted in transient decreases in HR and MBP, the drug is well-tolerated in pediatric patients. Our study provides a new clinical application for the rapid intravenous injection of DEX for the prevention and treatment of EA.

\section{Abbreviations \\ BIS: Bispectral index; DEX: Dexmedetomidine; EA: Emergence agitation; ECG: Electrocardiogram; HR: Heart rate; IV: Intravenous injection; LMA: Laryngeal mask airway; MBP: Mean blood pressure; m- CHOPES: Modified Children's Hospital of Eastern Ontario Pain Scale; PACU: Post-anesthesia care unit; PAED: Pediatric Anesthesia Emergence Delirium; $\mathrm{SaO}_{2}$ : Blood oxygen saturation; SD: Standard deviation}

\section{Acknowledgements}

We would like to thank the following team members for their contributions to the success of this trial.

\section{Funding}

The research was funded by Wenzhou City Public Welfare Science and Technology Project of China (Y20170139).

\section{Availability of data and materials}

The datasets used and analysed during the current study are available from the corresponding author on reasonable request.

\section{Authors' contributions}

FC analyzed and interpreted the patient data regarding the MBP, HR, ED, adverse events, bradycardia and recovery time. CYW analyzed demographic and surgical characteristics of patients. $\mathrm{YL}$ and $\mathrm{MMH}$ were a major contributor in writing the manuscript. All authors read and approved the final manuscript.

\section{Ethics approval and consent to participate}

Ethical approval for the clinical trial, was obtained from the Ethics Committee of the 2nd Affiliated Hospital of Wenzhou Medical University (No 2016-54), and written informed consent was obtained from parent of each child.

\section{Consent for publication}

None.

\section{Competing interests}

The authors declare that they have no competing interests.

\section{Publisher's Note}

Springer Nature remains neutral with regard to jurisdictional claims in published maps and institutional affiliations.

\section{Author details}

'Department of Pain Management, Shandong Provincial Hospital affiliated to Shandong University, 324 Jingwu Road, Jinan 250021, China. ${ }^{2}$ Department of Anesthesiology, Critical Care and Pain Medicine, The 2nd Affiliated Hospital \& Yuying Children's Hospital of WenZhou Medical University, Wenzhou, China.
Received: 12 December 2017 Accepted: 17 July 2018

Published online: 07 August 2018

\section{References}

1. Su X, Meng ZT, Wu XH, et al. Dexmedetomidine for prevention of delirium in elderly patients after non-cardiac surgery: a randomised, double-blind, placebo-controlled trial. Lancet. 2016;388:1893-902.

2. Riker RR, Shehabi Y, Bokesch PM, et al. Dexmedetomidine vs midazolam for sedation of critically ill patients: a randomized trial. JAMA. 2009:301:489-99.

3. Linares SB, García CMA, Ramírez CIL, et al. Pre-anesthetic medication with intranasal dexmedetomidine and oral midazolam as an anxiolytic. A clinical trial. An Pediatr (Barc). 2014;81:226-31.

4. Mason KP, Kelhoffer ER, Prescilla R, et al. Feasibility of measuring memory response to increasing dexmedetomidine sedation in children. $\mathrm{Br} J$ Anaesth. 2017:118:254-63.

5. Mason KP, Lerman J. Review article: Dexmedetomidine in children: current knowledge and future applications. Anesth Analg. 2011;113:1129-42.

6. Su F, Gastonguay MR, Nicolson SC, et al. Dexmedetomidine pharmacology in neonates and infants after open heart surgery. Anesth Analg. 2016;122:1556-66.

7. Vlajkovic GP, Sindjelic RP. Emergence delirium in children: many questions, few answers. Anesth Analg. 2007;104:84-91.

8. Cole JW, Murray DJ, McAllister JD, et al. Emergence behaviour in children defining the incidence of excitement and agitation following anaesthesia. Paediatr Anaesth. 2002:12:442-7.

9. Sato M, Shirakami G, Tazuke-Nishimura M, et al. Effect of single-dose dexmedetomidine on emergence agitation and recovery profiles after sevoflurane anesthesia in pediatric ambulatory surgery. J Anesth. 2010;24:675-82.

10. Ibacache ME, Muñoz HR, Brandes V, et al. Single-dose dexmedetomidine reduces agitation after sevoflurane anesthesia in children. Anesth Analg. 2004;98:60-3. table of contents

11. Jooste EH, Muhly WT, Ibinson JW, et al. Acute hemodynamic changes after rapid intravenous bolus dosing of dexmedetomidine in pediatric heart transplant patients undergoing routine cardiac catheterization. Anesth Analg. 2010;11:1490-6.

12. Hauber JA, Davis PJ, Bendel LP, et al. Dexmedetomidine as a rapid bolus for treatment and prophylactic prevention of emergence agitation in anesthetized children. Anesth Analg. 2015:121:1308-15.

13. Mahmoud M, Mason KP. Dexmedetomidine: review, update, and future considerations of paediatric perioperative and periprocedural applications and limitations. Br J Anaesth. 2015;115:171-82.

14. Xia ZQ, Chen SQ, Yao X, et al. Clinical benefits of dexmedetomidine versus propofol in adult intensive care unit patients: a meta-analysis of randomized clinical trials. J Surg Res. 2013;185:833-43.

15. Dawes J, Myers D, Görges M, et al. Identifying a rapid bolus dose of dexmedetomidine (ED50) with acceptable hemodynamic outcomes in children. Paediatr Anaesth. 2014:24:1260-7.

16. Makkar JK, Bhatia N, Bala I, et al. A comparison of single dose dexmedetomidine with propofol for the prevention of emergence delirium after desflurane anaesthesia in children. Anaesthesia. 2016;71:50-7.

17. Hall JE, Uhrich TD, Barney JA, et al. Sedative, amnestic, and analgesic properties of small-dose dexmedetomidine infusions. Anesth Analg. 2000;90:699-705.

18. Shimotori H, Kawano M. Anesthetic management with Dexmedetomidine in patients with serious mental and physical disabilities undergoing dental treatment. Masui. 2016;65:414-7.

Ready to submit your research? Choose BMC and benefit from

- fast, convenient online submission

- thorough peer review by experienced researchers in your field

- rapid publication on acceptance

- support for research data, including large and complex data types

- gold Open Access which fosters wider collaboration and increased citations

- maximum visibility for your research: over 100M website views per year

At BMC, research is always in progress.

Learn more biomedcentral.com/submission 